http://dx.doi.org/10.32929/2446-8355.2018v27n4p407-423

\title{
DETERMINAÇÃO DO SISTEMA REPRODUTIVO DE PARENTAIS PARA PRODUÇÃO DE HÍBRIDOS ENTRE P. cincinnata Mast. E P. quadrangularis Linn
}

\author{
Flávio Flôres Britto ${ }^{1}$, Dêvisson Luan Oliveira Dias ${ }^{2 *}$, Cláudio Lúcio Fernandes Amaral ${ }^{3}$, \\ Eliane Mariza Dortas Maffei $^{4}$, Valcimar Dias Libarino ${ }^{5}$
}

\footnotetext{
${ }^{1}$ Doutorando, Agronomia, Universidade Estadual do Sudoeste da Bahia (UESB), Vitória da Conquista- BA.

${ }^{2}$ Mestrando, Botânica, Universidade de São Paulo (USP), São Paulo - SP. E-mail: devissonluandias@ gmail.com

${ }^{3}$ Prof. Pleno Doutor, Agronomia/Fitotecnia, Estadual do Sudoeste da Bahia (UESB), Jequiá, Bahia-BA

${ }^{4}$ Prof. Titular, Doutora, Genética Vegetal, Universidade Estadual do Sudoeste da Bahia (UESB), Vitória da Conquista - BA

${ }^{5}$ Agrônomo, Fitotecnia, Universidade Estadual do Sudoeste da Bahia (UESB), Vitória da Conquista- BA.
}

Recebido: 28/06/2017; Aceito: 04/09/2018

RESUMO: O objetivo deste trabalho foi estudar os parâmetros fenológicos mais comuns, a compatibilidade intraespecífica, o comportamento meiótico, a viabilidade polínica e a receptividade estigmática de Passiflora cincinnata e P. quadrangularis. Os estudos de compatibilidade intraespecífica foram realizados mediante estimativas da taxa de autoincompatibilidade. Quarenta botões florais, de diferentes tamanhos, foram coletados ao acaso em todos os genótipos de $P$. cincinnata e de $P$. quadrangularis, sendo vinte de cada espécie. Os dados referentes ao comprimento dos botões, relativos a cada estádio da microsporogênese, foram submetidos a análise de variância. $\mathrm{O}$ estudo de viabilidade polínica foi conduzido com os seis genótipos apresentando cada um sete repetições a serem analisadas. Os tratamentos consistiram de cinco horários de coleta. Os efeitos dos horários de coleta sobre a viabilidade polínica foram estudados por análise de regressão. Para os estudos de receptividade foram realizados testes histoquímicos nos genótipos. A análise de variância indicou que os genótipos apresentaram diferença significativa quanto ao número de flores. Observou-se que, de maneira geral, a polinização cruzada controlada apresentou o maior número de frutos obtidos, seguida da polinização aberta e por último a autopolinização, que não apresentou pegamento. Por meio da análise de variância, demonstrou-se haver diferença significativa entre os estádios de desenvolvimento para a variável comprimento de botão. As duas espécies analisadas tiveram viabilidade máxima às 9 horas e 30min, mantendo percentual próximo às 12 horas e 30min, havendo a partir daí um decréscimo na viabilidade atingindo o mínimo. Os estudos de receptividade apontaram serem os seis genótipos, receptivos nos diferentes horários investigados.

Palavras-chave: Compatibilidade intraespecífica. Parâmetros fenológicos. Viabilidade polínica.

\section{DETERMINATION OF THE REPRODUCTIVE SYSTEM OF PARENTING FOR PRODUCTION OF HYBRID BETWEEN $P$. cincinnata Mast. and $P$. quadrangularis Linn.}


ABSTRACT: The objective of this study was the most common phenological, intraspecific compatibility, meiotic behavior, pollen viability and stigmatic receptivity Passiflora cincinnata and $P$. quadrangularis. Intraspecific compatibility studies were performed on estimates of the rate of self-incompatibility. Forty floral buds of different sizes were collected randomly from all genotypes of $P$. cincinnata and $P$. quadrangularis, twenty in each species . The data relating to the length of the buttons on each stage of microsporogenesis were subjected to analysis of variance. The study of pollen viability was conducted with the six genotypes each having seven replicates to be analyzed. The treatments consisted of five collection times. The effects of collection schedules on pollen viability were studied by regression analysis. For studies of receptivity histochemical tests were performed on the genotypes. The analysis of variance indicated that the genotypes showed significant differences in the number of flowers. It was observed that, in general, the controlled crosspollination with the largest number of fruits obtained, followed by open pollination and selfpollination latter showed no such fixation. Through the analysis of variance, it was demonstrated a significant difference between the stages of development for the length variable button. The two species analyzed had the highest viability 9 hours and 30min, keeping close to the percentage 12 hours and 30min, having thereafter a decrease in viability reaching the minimum. The studies showed responsiveness of the six genotypes are receptive investigated at different times.

Key words: Compatibility intraspecific. Phenological. Pollen viability.

\section{INTRODUÇÃO}

A família Passifloraceae compreende 20 gêneros, dos quais o gênero Passiflora é o mais importante, compreendendo aproximadamente 530 espécies (FEUILLET e MACDOUGAL, 2007), dispersas nas regiões pantropicais. O Brasil e a Colômbia são os países com maior número de espécies. Cerca de 120 espécies são nativas do Brasil (BERNACCI et al., 2003), sendo 32 delas encontradas na Bahia, das quais algumas como $P$. mucugeana e P. cacaoensis são consideradas endêmicas.

A maioria das espécies de maracujá, mesmo apresentando flores completas, é incapaz de realizar autopolinização. Sendo esse mecanismo importante para manter altos níveis de heterozigose, uma vez que induz a alogamia e, consequentemente contribui para o aumento da variabilidade genética (LOSS et al., 2006). A necessidade de polinização cruzada em Passifloras ocorre principalmente pela autoincompatibilidade (BRUCKNER et al., 2002).

A determinação das estratégias a serem adotadas em um programa de melhoramento genético de plantas é fortemente influenciada pela biologia reprodutiva da espécie, especialmente quando se utilizam técnicas de polinização artificial para hibridação de espécies. Desta maneira, a possibilidade de cruzamento entre progenitores selecionados requer também o conhecimento, nos indivíduos a serem cruzados, do período em que o estigma se encontra receptivo ao grão de pólen e do período em que o grão de pólen está viável (STIEHL-ALVES e MARTINS, 2008). Essas informações são importantes, pois 
favorecem o planejamento e a execução das estratégias a serem adotadas em cruzamento, reduzindo assim mão de obra e tempo despendidos (COSTA et al., 2008).

Nesse contexto, o objetivo deste trabalho foi estudar os parâmetros fenológicos mais comuns: taxa de florescimento (TF), pico de florescimento e intensidade relativa de florescimento (\%IRF) (segundo OLLERTON e DAFNI, 2005), a compatibilidade intraespecífica, o comportamento meiótico, a viabilidade polínica e a receptividade estigmática de Passiflora cincinnata e P. quadrangularis.

\section{MATERIAL E MÉTODOS}

Foram avaliados seis genótipos, sendo três de $P$. cincinnata Mast e três de $P$. quadrangularis Linn. Os genótipos utilizados são do campo experimental da Universidade Estadual do Sudoeste da Bahia (UESB), situado no município de Vitória da Conquista, Bahia (14 51' Latitude Sul, 40 50' Latitude Oeste, à uma altitude de 928m).

As plantas foram mantidas sob sistema de condução do tipo espaldeira, em campo aberto. Mensalmente foram realizadas podas e a adubação com a formulação NPK (4-14-8) a cada 60 dias durante 1 ano. A irrigação foi realizada pelo sistema de gotejamento. As avaliações iniciaram por ocasião do florescimento de cada genótipo, fato que ocorreu no mês de novembro de 2011 com os genótipos de Passiflora quadrangularis e no mês de dezembro de 2011 nos genótipos de $P$. cincinnata. A frutificação dos acessos das duas espécies aconteceu no início de janeiro de 2012.

O número de flores foi registrado diariamente em todas as plantas em estudo, de dezembro de 2011 a janeiro de 2012, para obtenção dos seguintes dados: a) épocas de início florescimento; c) horário da abertura da flor; c) número de flores abertas por planta/dia durante seis semanas de cada genótipo.

Com base nesses dados foram calculados (DAFNI, 1992):

. Taxa de florescimento (TF): percentagem cumulativa de flores na antese.

$$
T F=\frac{n^{\circ} \text { total flores }}{n^{\circ} \text { dias }}
$$

. Pico de florescimento: maior $\mathrm{n}^{\circ}$ de flores alcançadas em um dia.

. Intensidade relativa de florescimento (\%IRF): incremento percentual cumulativo de flores ao dia:

$$
\% I R F=\frac{n^{\circ} \text { de flores dia pico }}{n^{\circ} \text { total flores }}: n^{\circ} \text { repetições } x 100
$$

Os estudos de compatibilidade intraespecífica foram realizados mediante estimativas da taxa de autoincompatibilidade. Para isso foram realizados os seguintes tipos de polinização: polinização aberta, polinização cruzada controlada e autopolinização controlada. Para observação de polinização aberta, botões florais próximos à antese foram marcados com fitas coloridas, posteriormente foram contadas as flores com frutos em início de desenvolvimento. Para estimativa da autopolinização controlada, botões florais próximos à antese foram protegidos com sacos de papel um dia antes da abertura. As flores foram autopolinizadas com auxílio de cotonete e protegidas novamente por sacos de papel, por $24 \mathrm{~h}$ após a polinização. 
Para estimativa da polinização cruzada controlada, as flores foram emasculadas antes do momento da abertura e protegidas com sacos de papel. Os estigmas foram polinizados com pool de pólen de diferentes plantas (polinização cruzada), e as flores foram novamente protegidas por $24 \mathrm{~h}$. Para todos os casos (polinização aberta e controlada), dez flores foram utilizadas e depois de polinizadas foram identificadas por fitas coloridas e cinco dias após a polinização foi verificada a taxa de pegamento. $O$ número de frutos originários das polinizações foi registrado e os mesmos foram cobertos com sacos de papel para proteção contra queda no amadurecimento (BRUCKNER e OTONI, 1999). Os dados obtidos foram utilizados nas estimativas das taxas de autopolinização e autoincompatibilidade. Os dados referentes ao percentual de frutos vingados em relação ao número de flores polinizadas por tipo de polinização foram submetidos à análise de variância e teste de médias (Tukey p < 0,05). As análises foram realizadas no programa SISVAR (FERREIRA, 2008).

Foi utilizado o índice ISI ("Index to measure Self-Incompatibility"), de acordo com DAFNI (1992):

$$
I S I=\frac{N \text { ㅇe frutos provinientes de autopolinização }}{\text { № de frutos de polinização cruzada }}
$$

Os valores de ISI refletem as seguintes possibilidades:

a) $\geq 1$ autocompatível;

b) $\geq 0.2<1$ parcialmente autoincompatível;

c) $<0.2$ quase autoincompatível;

d) 0 completamente autoincompatível.

A taxa de pegamento (número de frutos) após autopolinização artificial foi utilizada para definir as classes de autoincompatibilidade (DAFNI, 1992):

a) autoincompatível $=0-3 \%$, classe 0 ;

b) levemente autocompatível $=3-30 \%$, classe 1 ;

c) altamente autocompatível $=>30 \%$, classe 2 .

Quarenta botões florais, de diferentes tamanhos, foram coletados ao acaso em todos os genótipos de $P$. cincinnata e de $P$. quadrangularis, sendo vinte de cada espécie. Os botões foram fixados em etanol-ácido acético 3:1. No momento do preparo da lâmina, os comprimentos dos botões com brácteas foram medidos com auxílio de paquímetro digital. Anteras de cada botão foram maceradas sobre a lâmina em carmin acético a $1 \%$ e observadas ao microscópio óptico para registro da fase meiótica. Os dados referentes ao comprimento dos botões, relativos a cada estádio da microsporogênese, foram submetidos a análise de variância.

O estudo de viabilidade polínica foi conduzido com seis genótipos (três $P$. cincinnata e três $P$. quadrangularis) apresentando cada um, sete repetições a serem analisadas. Os tratamentos consistiram de cinco horários de coletas, feitas às 6:30hs, 9:30hs, 12:30hs, 15:30hs e 18:30hs com $P$. quadrangularis e $P$. cincinnata. Em cada horário de coleta as anteras foram transferidas para frascos. Em seguida à coleta, foram preparadas as lâminas, nas quais foram contados 300 grãos de pólen por horário e repetição, totalizando 63000 grãos de pólen analisados. Os mesmos foram classificados em normais/viáveis (corados) e anormais/inviáveis (não corados ou com citoplasma retraído) com base na reação de 
coloração de grãos de pólen em carmim acético a 2\% (DAFNI, 1992). Os efeitos dos horários de coleta sobre a viabilidade polínica foram estudados por análise de regressão.

Para os estudos de receptividade foram realizados testes histoquímicos nos genótipos de $P$. cincinnata e $P$. quadrangularis. Os tratamentos consistiram de cinco horários, com intervalo de 3 hora, a partir das 6:30hs da manhã. Foi utilizado o peróxido de hidrogênio $\left(\mathrm{H}_{2} \mathrm{O}_{2}\right)$, que indica receptividade pela presença de peroxidase (OSBORN et al., 1998) através da formação de bolhas de ar (PEARSE, 1972). Nesse processo botões florais em pré-antese foram protegidos com sacos de papel. No dia seguinte a proteção, após abertura das flores os estigmas foram coletados nos respectivos horários e transferidos para vidros contendo a solução - teste, sendo mantidos totalmente submersos no peróxido de hidrogênio. Os estigmas foram classificados em receptivos se o filete estigmático atingisse a cor preta e formasse bolhas. Para obter resultados confiáveis, estigmas danificados ou com pólen na superfície não foram utilizados, evitando-se resultado falso positivo.

\section{RESULTADOS E DISCUSSÃO}

Em $P$. cincinnata, o tempo desde a formação do botão à abertura da flor foi de aproximadamente 25 dias. Estas abriram a partir das 6:30hs e permaneceram assim até às 19hs. Já para os genótipos de $P$. quadrangularis isto aconteceu por volta de 20 dias, com as flores abrindo às $6 \mathrm{hs}$ e fechando em torno de 18:30hs, caracterizado pelo murchamento das pétalas.

Tabela 1.1. Resumo da análise de variância do número de flores dos genótipos $P$. cincinnata. Vitória da Conquista-BA/UESB, 2013. Summary of the analysis of variance of the number of flowers of genotypes P. cincinnata. Vitória da Conquista-BA / UESB, 2013.

\begin{tabular}{lllll}
\hline FV & GL & SQ & QM & Fc \\
\hline Tratamentos & 2 & 88,36333 & 44,18167 & $45,7630 * *$ \\
Resíduo & 15 & 14,48167 & 0.96544 & \\
\hline Total & 17 & 102,84500 & &
\end{tabular}

FV - fonte de variação; GL - grau de liberdade; **1\% de probabilidade pelo teste Tukey; SQ - soma dos quadrados; MQ-média dos quadrados; F - valor calculado. FV - source variation; $G L$ - degree of freedom; ** $1 \%$ probability by Tukey test; $S Q$ - sum of squares; $M Q$ - mean squares; $F$ - calculated value.

Tabela 1.2. Resumo da análise de variância do número de flores dos genótipos $P$. quadrangularis. Vitória da Conquista-BA/UESB, 2013. Summary of the analysis of variance of the number of flowers of the P. quadrangularis genotypes. Vitória da Conquista-BA / UESB, 2013.

\begin{tabular}{lllll}
\hline FV & GL & SQ & QM & Fc \\
\hline Tratamentos & 2 & 8.12444 & 4.06222 & 14.3036 ** \\
Resíduo & 15 & 4.26000 & 0.28400 & \\
\hline Total & 17 & 12.38444 & &
\end{tabular}

FV - fonte de variação; GL - grau de liberdade; **1\% de probabilidade pelo teste Tukey; SQ - soma dos quadrados; MQ - média dos quadrados; F - valor calculado. FV - source variation; $G L$ - degree of freedom; ** $1 \%$ probability by Tukey test; $S Q$ - sum of squares; $M Q$ - mean squares; $F$ - calculated value. 
A análise de variância indicou que os genótipos apresentaram diferença significativa quanto ao número de flores (Tabela $1.1 ; 1.2 ; 1.3$ ). Houve distinção entre o genótipo HUESB1001 ( $P$. cincinnata) e os demais, tendo esse maior número de flores. O genótipo HUESB1002 $(P$. cincinnata) apresentou semelhança com o genótipo HUESB1004 ( $P$. quadrangularis), contudo superou em número os genótipos HUESB1003 (P. cincinnata), e os genótipos 1005 e 1006 (P. quadrangularis). O genótipo 1006 teve os menores números de flores no período investigado (Tabela 2).

Os genótipos de $P$. cincinnata apresentam distinção entre si, bem como aqueles de $P$. quadrangularis. Isto indica variabilidade genética. Em razão das plantas terem sido obtidas por reprodução sexuada e, submetidas a condições similares, as diferenças evidenciadas na produção de flores demonstram expressões distintas dos produtos gênicos, uma vez que a condição ambiental foi equitativa.

Tabela 1.3. Resumo da análise de variância do número de flores dos genótipos $P$. cincinnata e $P$. quadrangularis. Vitória da Conquista-BA/UESB, 2013. Summary of variance analysis of the number of flowers of $P$. cincinnata and P. quadrangularis genotypes. Conquista-BA / UESB, 2013.

\begin{tabular}{lllll}
\hline FV & GL & SQ & QM & Fc \\
\hline Genótipo & 5 & 145,450292 & 29,090058 & $46,314^{*}$ \\
Erro & 30 & 18,843183 & 0,628106 & \\
\hline
\end{tabular}

Total $35 \quad 164,293475$

FV - fonte de variação; GL - grau de liberdade; *5\% de probabilidade pelo teste Tukey; SQ - soma dos quadrados; MQ - média dos quadrados; F - valor calculado. FV - source variation; GL - degree offreedom; * 5\% probability by Tukey test; $S Q$ - sum of squares; $M Q$ - mean squares; $F$ - calculated value.

O número mais elevado de flores em $P$. cincinnata, e com superioridade de um dos genótipos, ao longo das semanas investigadas, revela ser essa espécie, dentre as analisadas, aquela que tem maior chance de formar frutos, uma vez que a partir da floração ocorrerá frutificação.

Tabela 2. Número médio semanal de flores dos genótipos de $P$. cincinnata e $P$. quadrangularis Vitória da Conquista-BA/UESB, 2013. Mean weekly number of flowers of $P$. cincinnata and P. quadrangularis genotypes Vitória da Conquista-BA / UESB, 2013.

\begin{tabular}{|c|c|c|c|c|c|c|c|c|}
\hline \multirow[b]{2}{*}{ Espécie } & \multirow[b]{2}{*}{ Genótipo } & \multicolumn{6}{|c|}{ Semana } & \multirow[b]{2}{*}{ Média $^{1}$} \\
\hline & & $1^{\mathrm{a}}$ & $2^{a}$ & $3^{a}$ & $4^{a}$ & $5^{a}$ & $6^{a}$ & \\
\hline \multirow{3}{*}{ P. cincinnata } & HUESB1001 & 5,1 & 8,0 & 7,0 & 8,2 & 7,5 & 6,7 & $7,1^{\mathrm{a}}$ \\
\hline & HUESB1002 & 3,0 & 3,4 & 2,0 & 3,2 & 3,8 & 4,8 & $3,4 \mathrm{~b}$ \\
\hline & HUESB1003 & 2,0 & 0,8 & 0,8 & 2,7 & 1,7 & 2,8 & $1,8 \mathrm{~cd}$ \\
\hline \multirow{3}{*}{ P. quadrangularis } & HUESB1004 & 2,1 & 2,2 & 2,7 & 3,7 & 3,5 & 1,8 & $2,7 \mathrm{bc}$ \\
\hline & HUESB 1005 & 1,7 & 0,8 & 1,1 & 0,8 & 1,0 & 1,0 & $1,0 \mathrm{~d}$ \\
\hline & HUESB1006 & 1,5 & 2,1 & 1,4 & 1,0 & 1,7 & 1,5 & $1,5 \mathrm{~cd}$ \\
\hline
\end{tabular}

${ }^{1}$ Médias seguidas de letras diferentes diferem significativamente pelo teste Tukey ao nível de 5\% de significância. ${ }^{1}$ Means followed by different letters differ significantly by the Tukey test at the 5\% level of significance. 
Salazar et al. (2016) verificaram que a combinação entre $P$. edulis / $P$. edulis aos 30 dias apresentou número médio de 7,81. Valor próximo do genótipo de $P$. cincinnata. Este resultado favorece a utilização de indivíduos selvagens na produção de frutos, pois o $P$. edulis, que é um parâmetro importante, tem comercialização significativa devido a sua alta produtividade.

A abertura floral ocorreu de modo diferente entre as espécies, onde os genótipos 1004, 1005 e 1006 ( $P$. quadrangularis) iniciaram a abertura floral nas últimas semanas do mês de novembro de 2011, diferentemente dos genótipos HUESB 1001, 1002 e 1003 (P. cincinnata) que tiveram início da abertura de flores no início do mês de dezembro de 2011.

Os parâmetros fenológicos estão apresentados na Tabela 3. A maior taxa de florescimento, dentro do período analisado, foi de 7,11 no genótipo HUESB 1001 e a menor foi de 1,09 (genótipo HUESB1005). O pico de florescimento, em seis semanas, variou de três flores no genótipo HUESB1005 ( $P$. quadrangularis) a 14 flores no genótipo HUESB1001 ( $P$. cincinnata), ambos ocorrendo no mês de dezembro. A intensidade relativa de florescimento, pela avaliação feita, variou de 0,1114 no genótipo HUESB1001 a 0,1552 no genótipo HUESB 1005 (Tabela 3).

Tabela 3. Taxa de florescimento (TF), pico de florescimento (PF) e intensidade relativa de florescimento (\%IRF) dos genótipos $P$. cincinnata e $P$. quadrangulares Vitória da Conquista$\mathrm{BA} / \mathrm{UESB}, 2013$. Flowering rate (TF), flowering peak (FP) and relative flowering intensity (\% RFI) of P. cincinnata and P. quadrangular genotypes Vitória da Conquista-BA / UESB, 2013.

\begin{tabular}{lcccc}
\hline Espécie & Genótipo & TF & PF & \% IRF \\
\hline \multirow{3}{*}{ P. cincinnata } & HUESB1001 & 7,11 & 14 & 0,1114 \\
& HUESB1002 & 3,5 & 7 & 0,1133 \\
P. quadrangularis & HUESB1003 & 1,83 & 5 & 0,1546 \\
& HUESB1004 & 2,73 & 6 & 0,1242 \\
& HUESB1005 & 1,09 & 3 & 0,1552 \\
& HUESB1006 & 1,5 & 4 & 0,1511 \\
\hline
\end{tabular}

Os resultados percentuais de pegamento das polinizações controladas (cruzada e autopolinização) e polinização aberta para os genótipos de $P$. cincinnata e $P$. quadrangularis estão apresentados na Tabela 4. Observa-se que, de maneira geral, a polinização cruzada controlada apresentou o maior número de frutos obtidos, seguida da polinização aberta e por último a autopolinização, que não apresentou pegamento.

A taxa de pegamento foi influenciada pelo genótipo, pelo tipo de polinização, contudo não houve interação genótipo x polinização (Tabela 5). A média percentual de pegamento dos frutos nos genótipos de $P$. cincinnata variou de 23,33\% a 66,67\% ambos nos genótipos respectivamente com polinização aberta e cruzada controlada.

No teste para autopolinização nenhuma das flores utilizadas produziu fruto, essas flores secaram e caíram sem apresentar qualquer sinal de frutificação. Esse fenômeno ocorreu tanto para os genótipos de $P$. cincinnata quanto para os de $P$. quadrangularis. 
Tabela 4. Percentual de pegamento de frutos por polinizações controladas e abertas em genótipos de P. cincinnata e P.quadrangularis, Vitória da Conquista-BA/UESB, 2013. Percentage of fruit glue by controlled and open pollinations in genotypes of $P$. cincinnata and P.quadrangularis, Vitória da Conquista-BA / UESB, 2013.

\begin{tabular}{|c|c|c|c|c|}
\hline & & \multicolumn{3}{|c|}{ Tipo de polinização } \\
\hline \multirow[t]{2}{*}{ Espécie } & Genótipo & Aberta $(\%)$ & Autopolinização (\%) & Cruzada $(\%)$ \\
\hline & HUESB1001 & 20,00 & 0 & 90,00 \\
\hline \multirow[t]{3}{*}{ P. cincinnata } & HUESB1002 & 20,00 & 0 & 50,00 \\
\hline & HUESB1003 & 30,00 & 0 & 60,00 \\
\hline & Média & 23,33 & 0 & 66,67 \\
\hline \multirow{4}{*}{ P. quadrangularis } & HUESB1004 & 60,00 & 0 & 80,00 \\
\hline & HUESB1005 & 50,00 & 0 & 70,00 \\
\hline & HUESB1006 & 20,00 & 0 & 20,00 \\
\hline & Média & 43,33 & 0 & 56,67 \\
\hline
\end{tabular}

Tabela 5. Resumo da análise de variância da taxa de pegamento de fruto resultante de dois tipos de polinização (aberta e cruzada controlada) realizada em diferentes genótipos de $P$. cincinnata e $P$. quadrangularis, Vitória da Conquista-BA/UESB, 2013. Summary of variance analysis of the fruit glue rate resulting from two types of pollination (open and crosscontrolled) in different genotypes of $P$. cincinnata and $P$. quadrangularis, Vitória da Conquista-BA / UESB, 2013.

\begin{tabular}{lcccc}
\hline FV & GL & SQ & QM & F \\
\hline Genótipo & 5 & 3,275000 & 0,655000 & $3,089^{*}$ \\
Polinização & 1 & 2,408333 & 2,408333 & $11,358^{*}$ \\
Genótipo x Polinização & 5 & 1,341667 & 0,268333 & $1,266 \mathrm{~ns}$ \\
\hline Resíduo & 108 & & & \\
\hline CV(\%) & 96,94 & & & \\
\hline
\end{tabular}

*Significativo a $5 \%$ de probabilidade pelo teste $\mathrm{F} . *$ Significant at $5 \%$ probability by $\mathrm{F}$ test.

$\mathrm{O}$ índice de autoincompatibilidade (ISI) encontrado para os genótipos de $P$. cincinnata e $P$. quadrangularis foi zero, indicando-as como autoincompatíveis, classe 0 (0-3\% de taxa de pegamento de autopolinização), segundo (DAFNI, 1992). A inexistência da autopolinização confirma a autoincompatibilidade e a alogamia dos genótipos, o que pode ser favorável à hibridação interespecífica. Souza (2014) encontrou o percentual médio de 43,33\% para polinização cruzada controlada e $11,66 \%$ para autopolinização controlada em $P$. subrotunda. Britto (2017) observou que o maior percentual médio de flores fertilizadas com consequente produção de frutos em $P$. trintae ao longo do período de abertura da flor foi de 53,33\% para polinização cruzada controlada, seguida da autopolinização controlada de $6,66 \%$.

Por meio da análise de variância, demonstrou-se haver diferença significativa entre os estádios de desenvolvimento para a variável comprimento de botão tanto em $P$. cincinnata quanto $P$. quadrangularis (Tabela 6). As fases da meiose I puderam ser diferenciadas em relação às médias dos tamanhos de botão, apesar dos botões de tamanhos semelhantes apresentaram-se em fases meióticas diferentes, contudo as fases da meiose II não foram diferenciadas para fins de análise de resultados. 
Para estudos no maracujazeiro envolvendo cultura in vitro quanto aos estádios de microsporogênese, em particular para as fases de meiose I, o mais indicado é a coleta de botões quando em tamanho aproximado de 4,55 mm-11,72 $\mathrm{mm}$ em $P$. cincinnata e em $P$. quadrangularis de 4,07-6,38 mm. Para as fases da meiose II, pode-se estimar um tamanho de 11,65-13,41 em P. cincinnata e 5-97-6,67 em P. quadrangulares (Figura 1).

Tabela 6. Estádios de meiose de genótipos de $P$. cincinnata e $P$. quadrangularis, associados aos valores mínimos, máximos e médios dos comprimentos de botão, em mm. Meiosis stages of genotypes of $P$. cincinnata and $P$. quadrangularis, associated to the minimum, maximum and average values of the button lengths, in $\mathrm{mm}$.

\begin{tabular}{|c|c|c|c|c|}
\hline \multirow[b]{2}{*}{ Estádios } & \multirow{2}{*}{$\begin{array}{l}\text { Comprimento de botão } \\
\text { P. cincinnata }(\mathrm{mm}) \\
\text { Valores }\end{array}$} & \multicolumn{3}{|c|}{$\begin{array}{l}\text { Comprimento de botão } \\
\text { P. qudrangularis (mm) }\end{array}$} \\
\hline & & Média & Valores & Média \\
\hline Prófase I & $4,55-6,41$ & 5,84 & $4,07-4,57$ & 4,31 \\
\hline Metáfase I & $6,54-8,42$ & 7,75 & $4,66-5,37$ & 5,03 \\
\hline Anáfase I & $8,27-09,88$ & 8,98 & $5,41-5,81$ & 5,56 \\
\hline Telófase I & $10,34-11,72$ & 11,06 & $5,92-6,38$ & 6,19 \\
\hline Meiose II & $11,65-13,41$ & 12,38 & $5,97-6,67$ & 6,39 \\
\hline
\end{tabular}

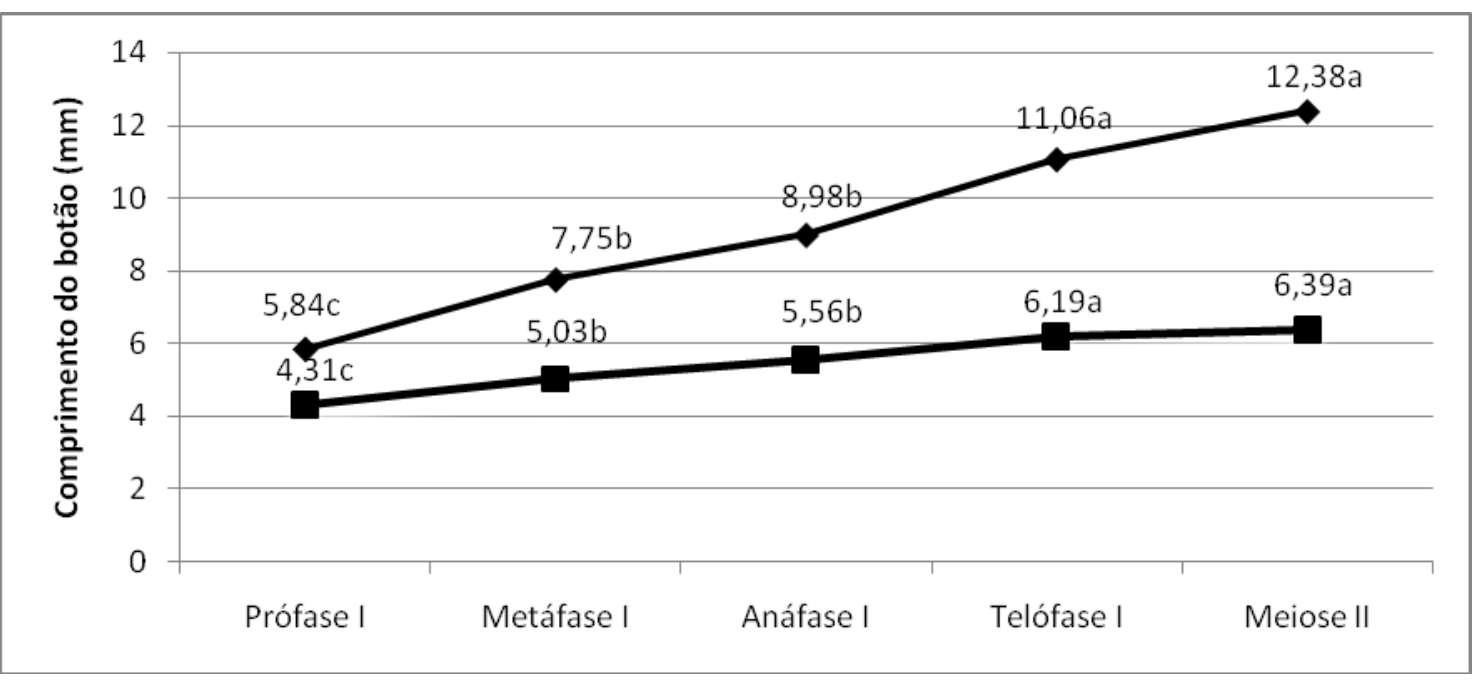

Médias seguidas pela mesma letra não diferem significativamente entre si pelo Teste de Tukey $(5 \%$ de probabilidade). Means followed by the same letter do not differ significantly from each other by Tukey's test (5\% probability).

Figura 1. Valores médios dos comprimentos de botão de genótipos de $P$. cincinnata e $P$. quadrangularis em função dos estádios de meiose. Mean values of the bud lengths of $P$. cincinnata and P. quadrangularis genotypes as a function of meiosis stages.

As análises realizadas no comportamento meiótico das espécies de $P$. cincinnata e $P$. quadrangularis permitiram observar pareamento regular com 9 bivalentes e segregação normal. No entanto foram observadas formações de pontes na meiose I durante a anáfase em células de $P$. quadrangularis bem como aparecimento de cromossomo extranumerário nas mesmas, o que pode aumentar a diversidade genética nesta espécie. 
As duas espécies analisadas tiveram viabilidade máxima às 9hs30min, mantendo percentual próximo às $12 \mathrm{hs} 30 \mathrm{~min}$, havendo a partir daí um decréscimo na viabilidade atingindo o mínimo. A função quadrática com tendência côncava foi o modelo que melhor representou este comportamento. O percentual médio de viabilidade polínica foi influenciado negativamente pelo horário de coleta, tendo os menores valores encontrados no fim da tarde. Observa-se na Tabela 7 que o horário 9hs30min foi superior aos demais, sendo indicado para a realização de polinização. Às 12hs30min foram encontrados, em média 95,44\% e 97,14\% de grãos de pólen viáveis para as espécies $P$. cincinnata e $P$. quadrangularis respectivamente, números que também são considerados elevados. Nos horários de $15 \mathrm{~h} 30 \mathrm{~min}$ e $18 \mathrm{hs} 30 \mathrm{~min}$, a viabilidade polínica variou de 90,88-93,52\% em $P$. cincinnata e 95,30-95,90\% em $P$. quadrangularis.

Em híbridos somáticos de Passiflora edulis f. flavicarpa + Passiflora cincinnata Mast. (BARBOSA e VIEIRA, 1997), o índice mais baixo de viabilidade polínica foi de 72,9\%, em consequência de anormalidades meióticas observadas, como presença de univalentes, bivalentes, tetravalentes, e alterações, como a presença de cromossomos retardatários na placa metafásica e pontes anafásicas, que foram consideradas fatores causadores de grãos de pólen imperfeitos e, consequentemente, inviáveis. Nesses casos, porém, a regularidade meiótica e consequente viabilidade polínica dependem, principalmente, da homologia cromossômica entre as espécies envolvidas no cruzamento.

Houve relação entre a quantidade de polens viáveis e o período em horas após antese floral, tanto para os genótipos de Passiflora cincinnata quanto para Passiflora quadrangularis. Apesar da abertura floral dos genótipos de $P$. quadrangularis ocorrer às $6 \mathrm{hs}$ a coleta teve início às $6 \mathrm{hs} 30 \mathrm{~min}$. A quantidade de polens viáveis nos genótipos investigados apresentou relação quadrática, com tendência convexa das $6 \mathrm{hs} 30 \mathrm{~min}$ às $18 \mathrm{hs} 30 \mathrm{~min}$. $\mathrm{O}$ genótipo HUESB1003 de $P$. cincinnata variou com relação ao horário de 6hs30min dos demais, pois apresentou um valor baixo.

Os grãos de pólen dos genótipos analisados de P. cincinnata e P. quadrangularis tiveram coloração e forma semelhante. Quando inviáveis os pólens dos indivíduos investigados perderam o formato ou não se coloriram. Os grãos de pólen das duas espécies apresentaram ligação entre si, por meio de uma ponte, fenômeno conhecido como citomixia.

Os estudos de receptividade apontaram serem os seis genótipos, três de $P$. cincinnata e três $P$. quadrangularis, receptivos nos diferentes horários investigados, sendo o comportamento semelhante das $6: 30 \mathrm{hs}$ às $18: 30 \mathrm{hs}$. Houve formação de bolhas de ar, bem como o filete estigmático dos genótipos analisados atingiram cor preta.

Nos indivíduos de $P$. cincinnata foi registrado início da separação das sépalas e pétalas por volta de $5: 15 \mathrm{hs}$ estando a flor totalmente aberta às $6: 30 \mathrm{hs}$, mesmo horário observado por Alves et al. (2009). O horário registrado neste trabalho para fechamento das flores foi às $19 \mathrm{hs}$, momento semelhante ao relatado por Duarte et al. (2009). Não há relatos na literatura investigada do período de antese de Passiflora quadrangularis, sendo neste trabalho das $6 \mathrm{hs}$ às $18: 30 \mathrm{~min}$. 
Espécies de maracujá apresentam períodos de abertura floral diferentes, quase sempre curtos, dificilmente passando de oito horas, sendo geralmente o horário de antese e fechamento das flores adaptadas aos períodos de atividade dos polinizadores (COSTA et al., 2009). Existem diferentes horários para uma mesma espécie atribuída a diferentes condições climáticas, diferenças genéticas entre as plantas e a combinação de ambos os fatores (DUARTE, 1996).

A observação feita em ambos os genótipos das espécies corresponde ao período em que os mesmos estão aptos ao florescimento. Em $P$. cincinnata o florescimento e frutificação ocorrem em quase o ano todo (NUNES e QUEIROZ, 2006) mais especificamente de março a dezembro (DUARTE et al., 2009).

A taxa de florescimento indica o número médio de flores novas a cada dia (DAFNI, 1992) e esta indicou um baixo número de flores nos genótipos de $P$. quadrangularis.

As autopolinizações indicaram $P$. cincinnata e $P$. quadrangularis serem espécies autoincompatíveis. Estudos realizados por DUARTE et al. (2009) em P cincinnata mostra resultados semelhantes.

A determinação da alogamia, verificada neste trabalho, está relacionada a autoincompatibilidade, impedindo plantas produtoras de gametas masculinos e femininos funcionais produzam sementes quando autopolinizadas (BRUCKNER et al., 2005), sendo considerado mecanismo extremamente importante pois promove a manutenção da variabilidade genética (SCHIFINO-WITTMANN e DALL' AGNO, 2002). A incompatibilidade em Passiflora já foi citada como gametofítica (FALEIRO et al., 2000) quando o grão de pólen carrega um alelo também presente no estigma e que inibe o desenvolvimento do tubo polínico (SCHIFINO-WITTMANN e DALL'AGNOL, 2002). BRUCKNER (1994) relata a possibilidade de autofecundação quando flores estão em préantese.

O sucesso na produção de frutos e sementes, investigadas nesta pesquisa, dependeu também da presença de polinizadores na área, uma vez que as espécies são autoincompatíveis. Nas variedades cultivadas o agente polinizador mais efetivo de Passiflora é a mamangava (Xylocopa sp.) (SOUZA, 1994). Dessa forma o percentual de fertilização depende do número de polinizadores, o que pode ser afetado pela frequência de uso de defensivos agrícolas, por isso recomenda-se que as pulverizações em pomares de maracujazeiros sejam realizadas a noite ou pela manhã (JUNQUEIRA et al., 2001).

De acordo com as análises citológicas realizadas neste trabalho, o tamanho do botão floral não deve ser usado como parâmetro indicativo para fase meiótica durante a microsporogênese. LAUXEN et al. (1995) relacionaram os estádios de microsporogênese a quatro intervalos preestabelecidos de comprimento de botão floral em cultivares brasileiras de soja (Glycine $\max$ (L.) Merrill), esta relação é possível com o $P$. cincinnata e $P$. quadrangularis de acordo com o que foi investigado.

Outros parâmetros, além do tamanho de botão floral, podem ser associados aos estádios de desenvolvimento de estruturas reprodutivas. WILLCOX et al. (1990), em estudo feito com amendoim (Arachis hypogaea L.), demonstraram que, não o tamanho, como visto neste 
trabalho, mas sim o formato da base do botão floral forneceu boa correlação com o desenvolvimento do micrósporo, mesmo considerando que tais diferenças podem ocorrer por causa das condições ambientais, e não apenas como resultado de diferenças genotípicas. Em pimentão (Capsicum annum L.), as características morfológicas do botão floral puderam ser associadas ao estádio de micrósporo em todos os genótipos cujos botões tinham pétalas de tamanho igual ou pouco maior que as sépalas, e as anteras tinham traços de antocianina em sua extremidade (SILVA et al., 1995)

Os estudos meióticos realizados por STOREY (1950), BEAL (1969a), BEAL (1969b) e BARBOSA (1998) confirmam os dados deste trabalho com relação a distribuição cromossômica. Posteriormente, MELO et al. (2001) observaram esse mesmo comportamento com 9 bivalentes e segregação normal na anáfase em $P$. cincinnata.

As pontes anafásicas relatadas neste trabalho em células de Passiflora quadrangularis podem ser relacionadas com a má qualidade na produção de polens em decorrência de anormalidades da própria meiose da espécie. Este fato foi destacado por GOMES (1998) que informou ainda da presença de univalentes, bivalentes, e alterações como a presença de cromossomos retardatários na placa metafásica como fatores considerados causadores de grãos de pólen imperfeitos.

O cromossomo B verificado no Passiflora quadrangularis, é também chamado de extranumerário ou acessórios em fungos, plantas e animais. Esses cromossomos possuem um padrão de segregação não mendeliano, podendo existir de uma a várias cópias por indivíduo (BEUKEBOOM, 1994).

O menor valor médio encontrado neste trabalho foi de 90,88\% na média dos genótipos de Passiflora cincinnata no horário de 18hs30min. Segundo RUGGIERO et al., (1996) é ainda um alto percentual de viabilidade (acima de 70\%). Esses dados podem ser explicados pelo fato de o grão de pólen do maracujazeiro ser pegajoso, recoberto por uma substância chamada pollenkit que, dentre outras funções, atua como protetor, minimizando a desidratação do pólen e consequente perda de viabilidade (PACINI e FRANCHI, 1993)

Inviabilidade polínica, notada neste trabalho, pode ocorrer durante a microgametogênese, em que falhas no comportamento meiótico resultam em gametas com cromossomos desbalanceados ou anucleados, ou ainda durante a microgametogênese, resultando em grãos de pólen com citoplasma retraído (TWELL, 1995). A interferência do efeito do ambiente no comportamento meiótico, e consequentemente na viabilidade dos grãos de pólen, foi observado em Bougainvillea sp., quando foram comparadas variedades de várias regiões do Brasil (ADAMOWSKI et al., 1995).

A citomixia relatada em ambos os genótipos de maracujazeiro pode ser interpretada como transferência de material de uma estrutura para a outra, atribuída algumas vezes a deficiência na formação da parede celular, podendo ocorrer tanto em mitose quanto em meiose, podendo em alguns casos está ligada com o fenômeno de desgenerescência. Bhandari et al. (1969) observaram passagem de nucléolo de uma célula meiótica para outra, sem que isso afetasse a fertilidade do pólen, fato que pode ter ocorrido neste trabalho. Por outro lado 
LATTO et al. (2006) afirmam que a citomixia geralmente está associada com erros meióticos e consequentemente baixa fertilidade.

As flores de $P$. cincinnata estão receptivas durante toda a antese estando os estigmas flexionados ou não (VARASSIN e SILVA, 1999; KILL et al., 2010). Os estigmas de ambas as espécies mostraram-se com alta receptividade em todos os horários de coleta neste trabalho. DUARTE et al. (2009) relatam que $P$. cincinnata durante a abertura da flor o estigma já se encontrava receptivo. Apesar da receptividade as espécies se apresentam hercogamia, isto é, no inicio da antese o posicionamento dos estiletes erguidos faz com as flores se apresentem funcionalmente masculinas, ocasião em que as abelhas ao visitarem as flores se "sujam" de pólen, mas não tocam o estigma (KILL et al., 2010). A movimentação dos órgãos reprodutivos estabelece uma barreira temporal para a polinização em estigmas receptivos, mas não uma barreira fisiológica, pois o pólen está disponível durante a antese, e os estigmas estão receptivos, indicando que potencialmente as flores podem ser polinizadas durante toda antese (VARASSIN e SILVA, 1999). Foi observado em P. edulis que a eficiência da polinização está associada às adaptações morfológicas das flores aos visitantes, à sincronização temporal entre o horário de coleta das abelhas, abertura da flor e deflexão dos estiletes (SIQUEIRA et al., 2009), fato também verificado neste trabalho.

A quantidade de estigma polinizado pode também influenciar na taxa de pegamento bem como na característica do fruto (SIQUEIRA et al., 2009). Esses autores observaram no maracujá amarelo maior formação de frutos nas flores com três estigmas, quando todos eles foram utilizados na polinização cruzada, porém naquelas em que foi feita a polinização em apenas um estigma, obteve-se a formação de um único fruto, totalmente deformado.

\section{CONCLUSÃO}

Os genótipos estudados da espécie $P$. cincinnata e $P$. quadrangularis possuem antese diurna matutina.

As plantas das espécies $P$. cincinnata e $P$. quadrangularis são autoincompatíveis.

Os botões florais não devem ser usados como parâmetro indicativo para a fase meiótica durante a microsporogênese.

A viabilidade polínica das espécies P.cincinnata e $P$ quadrangularis se encontra elevada no turno matutino, sofrendo redução à tarde.

Os estigmas apresentam-se receptivos durante todo o dia, sendo ideal para realização de polinizações.

\section{AGRADECIMENTOS}

Ao programa de pós-graduação em Agronomia da Universidade Estadual do Sudoeste da Bahia - UESB. 


\section{REFERÊNCIAS BIBLIOGRÁFICAS}

ADAMOWSKI, E. V.; PAGLIARINI, M. S.; VALVA, F. D. A. Estudo comparativo do comportamento meiótico de variedades de Bougainvillea sp. cultivadas em diferentes regiões do Brasil. In: CONGRESSO NACIONAL DE GENÉTICA, 41, 1995, Caxambu. Resumos, Caxambu: SBG, 1995. p. 433.

ALVES, M. F.; SILVA, L. O.; YAMAMOTO, M.; BARBOSA, A. A. A.; OLIVEIRA, P. E. A. M.; SANO, S. M. Biologia Reprodutiva de três espécies de Passiflora L. (Passifloraceae) em Uberlândia, MG, Brasil. In: CONGRESSO DE ECOLOGIA DO BRASIL, 9, 2009, São Lourenço. Anais eletrônicos... São Paulo: SEB, 2009. Disponível em: < http://www.sebecologia.org.br/2009/resumos_ixceb/1267.pdf>. Acesso em:12 dez. 2012

BARBOSA, L. V. Citologia de híbridos somáticos de Passiflora spp. obtidos por fusão de protoplastos. 1998. 94 f.. (Doutorado em Agronomia - Genética e Melhoramento de Planta) Escola Superior de Agricultura Luiz de Queiroz, Universidade de São Paulo, Piracicaba, 1998.

BARBOSA, L. V.; VIEIRA, M. L. C. Meiotic behavior of passion fruit somatic hybrids, Passiflora edulis f. flavicarpa Degener + P. amethystine Mikan. Euphytica, Holanda, v. 98, n. 1-2, p.21-127, 1997.

BEAL, P. R. Chromosome numbers of exotic Passiflora species in Australian. Queensland Journal of Agricultral and Animal Sciences, Queensland, Austrália, v. 26, n. 1, p.73-81, $1969 \mathrm{~b}$

BEAL, P. R. Citology of the native Australian Passiflora species. 1. Chromosome number and horticultural value. Queensland Journal of Agricultural and Animal Sciences, Queensland, Austrália, v. 26, n. 3, p.407-421, 1969a.

BELO, G. O. Análises Morfológicas E Genéticas Em Progênie Híbrida F1 Do Cruzamento Passiflora gardneri Mast x Passiflora gibertii N. E. Brow. 2010. 112 f. (Mestrado Melhoramento de Plantas e Biotecnologia) - Universidade Estadual de Santa Cruz, Ilhéus, 2010.

BERNACCI L. C.; VITTA F. A.; BAKKER Y. V. Passifloraceae. In: WANDERLEY M. G. L.; SHEPPERD, G. J.; MELHEM, T. S.; GIULIETTI, A. M.; KIRIZAWA, M. Flora Fanerogâmica do Estado de São Paulo. 1 ed., v. 3. São Paulo: RIMA / FAPESP, 2003. cap.5 , p. 247-274.

BEUKEBOOM, L. W. Bewildering Bs: na impressiono $\mathrm{f}$ the 1stB-chromosome conference Heredity, Reino Unido, v. 73, n. 3, p.328-336, 1994.

BHANDARI, N. N.; TANDON, S. L.; JAIN, S. Some observations on the cytology and cytomixis in Canavalia DC. Cytologia, Japão, v. 34, n. 1, p.22-28, 1969.

BRITTO, F. F. Aspectos reprodutivos, crescimento in vitro e divergência genética por marcador ISSR em Passiflora trintae Sacco. 2017. 123 f. Tese (Doutorado em Agronomia Fitotecnia). Universidade Estadual do Sudoeste da Bahia, Vitória da Conquista, 2017. 
BRUCKNER, C. H. Autoincompatibilidade no maracujá (Passiflora edulis Sims). 1994. 85 f. Tese (Doutorado - Genética e Melhoramento) - Universidade Federal de Viçosa, Viçosa, 1994.

BRUCKNER, C. H.; SUASSUNA, T. D. M. F.; REGO, M. M.; NUNES, E. S. Auto incompatibilidade do maracujá-implicações no melhoramento genético. In: FALEIRO, F. G.; JUNQUEIRA; N. T. V., BRAGA, M. F. Maracujá: germoplasma e melhoramento genético. Planaltina: Embrapa Cerrados, 2005. cap. 13, p. 316-338.

BRUCKNER, C. H.; SUASSUNA, T. D. M. F.; REGO, M. M.; NUNES, E. S. Maracujazeiro. In: BRUCKNER, C. H. Melhoramento de fruteiras tropicais. Viçosa: UFV, 2002. p. 373-409.

BRUCKNER, C. H.; OTONI, W. C. Hibridação em maracujá. In: BORÉM, A. (Ed). Hibridação artificial de plantas. Viçosa: UFV, 1999. cap. 8, p. 379-399.

COSTA, L. V.; LOPES, M. T. G.; LOPES, R.; ALVES, S. R. M. Polinização e fixação de frutos em Capsicum chinense Jacq. Revista Acta Amazônica, Manaus, Amazonas, v. 38, n. 2, p.361-364, 2008.

COSTA, R. S.; MORO, F. V.; OLIVEIRA, J. C. Influência do momento de coleta sobre a viabilidade de grão de pólen em maracacujá - doce (Passiflora alata Curtis). Revista Brasileira de Fruticultura, Jaboticabal, São Paulo, v. 31, n. 4, p.956-961, 2009.

DAFNI, M. Pollination Ecology: a pratical approach. New York: Oxford University Press, 1992. $250 \mathrm{p}$.

OLLERTON, J.; DAFNI, A. Functional floral morphology and phenology. Practical pollination biology. Enviroquest, Cambridge, 2005. cap. 1, p. 1-26.

DUARTE, J. Aspectos do florescimento e caracterização do fruto do maracujá caerulea (Passiflora caerulea L.). 1996. 72 f. Tese (Agronomia - Horticultura) - Faculdade de Ciências Agrárias, Universidade Estadual Paulista, Botucatu, 1996.

FERREIRA, D. F. SISVAR: um programa para análises e ensino de estatística. Revista Symposium, Lavras, v. 6, n. 2, p.36-41, 2008.

FEUILlET, C.; MACDOUGAL, J. M. Passifloraceae. In: KUBITZI, K. (Ed.). The Families and Genera of Vascular Plants. Universidade de Hamburgo, Berlin: Springer, 2007, cap. 7, p. 270-281.

GOMES, P. R. Viabilidade e conservação do grão de pólen de cebola (Allium cepa L.). 1998, 54 f. Dissertação (Mestrado em Ciência e Tecnologia de Sementes) - Universidade Federal de Pelotas, Pelotas, 1998.

JUNQUEIRA, N. T. V.; VERAS, M. C. M.; NASCIMENTO, A. C.; COSTA CHAVES, R.; MATOS, A. P.; JUNQUEIRA, K. P. A importância da polinização manual para aumentar a produtividade do maracujazeiro. 1. ed. Brasília: Embrapa, 2001. 18 p. Disponível em: <www.embrapa.br>. Acesso em: 14 dez. 2012. 
LOSS, A. C. C.; LEITE, Y. L.; LOURO, I. D.; BATITUCCI, M. D. C. P. Diversidade genética de populações de maracujá-doce (Passiflora alata Curtis) no estado do Espírito Santo, Brasil. Natureza on line, Santa Tereza, v. 4, n. 2, p.55-61, 2006.

MELLINGER, L. L.; RICHERS, B. T. Fenologia de espécies oleaginosas na RDS Amaña (AM) - dados parciais. $2005 . \quad$ Disponível em: $<$ http://www.mamiraua.org.br/arq/Mellinger\&Richers-FenologiaOleaginosasAmanaSAPII.pdf $>$. Acesso em: $28 \mathrm{dez} .2012$.

MELO, N. F.; CERVI, A. C.; GUERRA, M. Karyology and cytotaxonomy of the genus Passiflora L. (Passifloraceae). Plant Systematics and Evolution, New York, v. 226, n. 1-2, p.69-84, 2001.

NUNES, T. S.; QUEIROZ, L. P. Flora da Bahia: Passifloraceae. Sitientibus, Feira de Santana, v. 6, n. 3, p.194-226, 2006.

OLLERTON, J.; DAFNI, A. Functional floral morphology and phenology. In: DAFNI, A.; KEVAN, P. G.; HUSBAND, B. C. (Eds.). Practical Pollination Biology. Cambridge: Enviroquest Ltd., 2005. cap. 1, p. 1-26.

OSBORN, M. M.; KEVAN, P. G.; LANE, M. A. Pollination biology of Opuntia polyacantha and Opuntia phaeacantha (Cactaceae) in southern Colorado. Plant Systematics and Evolution, New York, v. 159, n. 1-2, p.85-94, 1998.

PACINI, E.; FRANCHI, C. G. Role of the tapetum and pollen and spore dispersal. Plant Systematics and Evolution, New York, v. 7, suppl., p.1-11, 1993.

PEARSE, A. G. E. Principles of oxidoreductase histochemistry. In: Histochemistry Theoretical and Applied. v. 2. Churchill Livingstone, Edinburgh. 1972. p. 880-920.

RUGGIERO, C.; SÃO JOSÉ, A. R.; VOLPE, C. A.; OLIVEIRA, J. D.; DURIGAN, J. F.; BAUMGARTNER, J. G.; PEREIRA, V. D. P. Maracujá para exportação: aspectos técnicos da produção. Brasília: EMBRAPA, 1996. cap. 1, p. 58-64. (FRUPEX)

SALAZAR, A. H.; SILVA D. F. P.; PICOLI, E. T.; BRUCKNER, C. H. Desenvolvimento, florescimento e análise morfoanatômica do maracujazeiroamarelo enxertado em espécies silvestres do gênero passiflora. Revista Brasileira de Ciências Agrárias, Recife, v. 11, n. 4, p.323-329, 2016.

SCHIFINO-WITTMANN, M. T.; DALL'AGNOL, M. Autoincompatibilidade em plantas. Ciência Rural, Santa Maria, v. 32, n. 6, p.1083-1090. 2002.

SILVA, F. J. T.; SCHWADE, M. R. M.; WEBBER, A. C. Fenologia, biologia floral e polinização de Erythroxylum cf macrophyllum (Erythroxylaceae), na Amazônia Central. Revista Brasileira de Biociências, Porto Alegre, v. 5, supl. 1, p.186-188, 2007.

SILVA, R.; LUZ, J. M. Q.; DAVIDE, L. C.; PINTO, J. E. B. P. Relação entre microsporogênese e tamanho do botão floral em pimentão (Capsicum annum L.). In: CONGRESSO NACIONAL DE GENÉTICA, 41, 1995, Caxambu. Anais. Caxambu: SBG, 1995. p. 433. 
SIQUEIRA, K. M. M. D.; KIILL, L. H. P.; MARTINS, C. F.; LEMOS, I. B.; MONTEIRO, S. P.; FEITOZA, E. D. A. Ecologia da polinização do maracujá-amarelo, na região do vale do submédio São Francisco. Revista Brasileira de Fruticultura, Jaboticabal, v. 31, n. 1, p.1-12, 2009.

SOUZA, P. J. S. Polinização em maracujazeiro. In: SÃO JOSÉ, A. R. (Ed.). Maracujá, produção e mercado. Vitória da Conquista: DFZ/UESB; 1994. p. 65-70.

SOUZA, V. O. Caracterização morfológica, reprodutiva, fisiológica e anatômica em Passiflora subrotunda Mast. submetida a diferentes níveis de sombreamento. 2014. $114 \mathrm{f}$. Dissertação (Mestrado em Produção Vegetal) - Universidade Estadual de Santa Cruz, Ilhéus, 2014.

STIEHL-ALVES, E. M.; MARTINS, M. P. Biologia reprodutiva de Acacia mearnsii De Wild.:receptividade de estigmas. Revista Árvore, Viçosa, v. 32, n. 4, p.609-616, 2008.

STOREY W. B. Chromosome numbers of some species of Passiflora occurring in Hawaii. Pacific Science, Hawaii, v. 4, p.37-42, 1950.

TWELL, D. Diphtheria toxin-mediated cell ablation in developing pollen: vegetative cell ablation blocks generative cell migration. Protoplasma, New York, v. 187, n. 1-4, p.144-154, 1995.

VARASSIN, I. G.; SILVA, A. G. A melitofilia em Passiflora alata Dryander (Passifloraceae), em vegetação de restinga. Rodriguésia, Rio de Janeiro, v. 50, n. 76-77, p.517, 1999.

VIANA, A. J. C.; AHNERT D.; CORRÊA R. X.; ARAÚJO I. S.; BERNACCI, L. C.; LAWINSCKY, P. R.; SOUZA, M. M. Caracterização morfológica e polínica em Passiflora edulis e Passiflora cacaoensis para utilização como genitoras em hibridações interespecíficas. In: CONGRESSO BRASILEIRO DE MELHORAMENTO DE PLANTAS, 5, Guarapari. Anais... Guarapari: CBPM, 2009. CD-ROM.

WILlCOX, M. C.; REED, S. M.; BURNS, J. A.; WYNNE, J. C. Microsporogenesis in peanut (Arachis hypogaea). American Journal of Botany, Ohio, v. 77, n. 10, p.1257-1259, 1990. 